\title{
Infiltration under Ponded Conditions
}

\author{
Ioannis Argyrokastritis *(D), Maria Psychogiou and Paraskevi A. Londra *(D)
}

Laboratory of Agricultural Hydraulics, Department of Natural Resources Management and Agricultural Engineering, School of Environment \& Agricultural Engineering, Agricultural University of Athens, 75 Iera Odos Street, 11855 Athens, Greece; lhyd4psm@aua.gr

* Correspondence: jarg@aua.gr (I.A.); v.londra@aua.gr (P.A.L.)

check for updates

Citation: Argyrokastritis, I.;

Psychogiou, M.; Londra, P.A.

Infiltration under Ponded Conditions Water 2021, 13, 3492. https://

doi.org/10.3390/w13243492

Academic Editors: Roberto Greco,

George Kargas, Petros Kerkides and

Paraskevi Londra

Received: 6 October 2021

Accepted: 3 December 2021

Published: 7 December 2021

Publisher's Note: MDPI stays neutral with regard to jurisdictional claims in published maps and institutional affiliations.

Copyright: (c) 2021 by the authors. Licensee MDPI, Basel, Switzerland. This article is an open access article distributed under the terms and conditions of the Creative Commons Attribution (CC BY) license (https:// creativecommons.org/licenses/by/ $4.0 /)$.
Abstract: Ponded infiltration processes occur in agricultural lands irrigated by flooding of their soil surface or under insufficient drainage conditions. The existing equations describing the phenomenon of vertical infiltration under ponded conditions have not considered the actual contribution of the pressure head gradient to the flow. In this study, simple equations are proposed to describe the horizontal and vertical infiltration under various ponding heads incorporating the actual contribution of the pressure head gradient to the flow. Six soils with known hydraulic properties, covering a wide range of soil textures, were used. Horizontal and vertical infiltration data are obtained by numerical simulation for all soils studied using the Hydrus-1D code. To validate the accuracy of the proposed equations, the solutions of horizontal and vertical infiltrations provided by the proposed equations were compared with numerically simulated ones provided by the Hydrus 1-D. The analysis of the results showed a very good agreement in all soils studied. The proposed vertical infiltration equation was also compared to a simple and accurate equation which does not incorporate the actual contribution of the pressure head gradient to the flow and differences between them were observed in all soils studied.

Keywords: ponding head; vertical infiltration; pressure head gradient; horizontal infiltration

\section{Introduction}

The infiltration process is of great importance in hydrology and agricultural sciences since it provides the water available for plants and groundwater recharge and defines water runoff at soil surface. A rainfall or irrigation intensity greater than soil infiltration capacity will lead to water runoff at the soil surface, causing ponded conditions. Additionally, in agricultural lands ponded conditions may be developed under insufficient drainage and in irrigation practices when irrigation water is applied by flooding the soil surface. Further ponded conditions are met in lakes, natural or artificial. Consequently, the study of the vertical infiltration under ponding heads is of great interest.

For this, Philip [1,2] tackled the problem of the vertical infiltration under ponded conditions, and he presented analytical solutions relative to this flow problem. Other researchers, later, investigated the same infiltration case and proposed equations to estimate the $\mathrm{cu}^{-}$ mulative ponded infiltration in a homogeneous soil [3-14]. The main difference among these equations is the number of physical or fitting parameters used. In several models, the common physical parameters used are the soil sorptivity, $S$, and the saturated hydraulic conductivity, $K_{s}$, which are often met as the main parameters of the two-parameter models.

Green and Ampt [3] proposed a two-parameter equation assuming a piston-type water content profile with a well-defined wetting front characterized by a constant pressure head and constant pressure head at the surface. Brutsaert [4] proposed a three-parameter equation based on the quasi-analytical time-series infiltration solution of Philip [5] which can be converted into a two-parameter form by fixing the value of the third parameter. Parlange et al. [6] proposed a three-parameter equation based on integration of the water content-based form of Richards' equation which can be converted into a two-parameter 
form by fixing the value of the third parameter. Parlange et al. [7] proposed a modified version of Parlange et al. [6] equation with five parameters including ponded conditions. Haverkamp et al. [8] proposed a very accurate six-parameter equation based on that of Parlange et al. [7] which can be converted into a three-parameter one. Swartzendruber [9] proposed a three-parameter equation which is a semi-analytical solution of the Richards' equation for all times $t>0$, which is similar to the Philip's moderate time series solution. This equation can be converted into the two-parameter equation of Stroosnijder [10] by fixing the third parameter. Later, Valiantzas [11] proposed a simple two-parameter linearized equation which is a specific solution located approximately at the middle of the two limiting behavior soils defined by the Green and Ampt [3] and Talsma and Parlange [12] equations. Valiantzas compared his equation with other common nonlinear ones with two and three parameters [3-10]. The comparison showed that the three-parameter equations may reproduce unrealistic estimates and have convergence or nonuniqueness difficulties of the solution [11]. The equation proposed by Valiantzas, over the other two-parameter equations studied, has the advantage of simplicity and accuracy of sorptivity and saturated hydraulic conductivity estimations, as well as the ability to detect and eliminate abnormalities of the infiltration process [11].

However, all the above-mentioned researchers did not incorporate into their analyses the actual contribution of the pressure head gradient to the flow.

Recently, Poulovassilis and Argyrokastritis [15] determined the exact contribution of the pressure head gradient term in the vertical infiltration process in the case of homogeneous porous media under zero ponding head. Specifically, Poulovassilis and Argyrokastritis [15] showed that the contribution to the flow of the pressure head gradient $S t^{1 / 2}$, included in Philip's [16] two term equation, is only applied in the case of horizontal infiltration. They defined analytically that this contribution is in the vertical case is $\left(S t^{1 / 2}-\alpha_{t}\right)$ and that it is smaller than the horizontal one by a factor $\alpha_{t}$, being a measurable function of the infiltration time $t$. In conclusion, they proposed a new two-term analytical equation for vertical infiltration which reproduces exactly a vertical cumulative curve and satisfies the physical rules of the infiltration process.

Up to now, no research has been carried out on the actual contribution of the pressure head gradient to flow during the vertical infiltration process under ponded conditions.

The purpose of the present study is to define the physical characteristics of infiltration under ponded conditions and to develop simple equations for it, conforming to these characteristics, incorporating the actual contribution of the pressure head gradient.

\section{Materials and Methods}

\subsection{Theory}

The infiltration process along the horizontal axis $x$ in a homogeneous semi-infinite porous body is governed by the following initial conditions

$$
\begin{gathered}
\theta=\theta_{i} \quad h=h_{i} \quad t=0 \quad x \geq 0, \\
\theta=\theta_{0} \quad h=h_{p} \quad t \geq 0 \quad x=0,
\end{gathered}
$$

where $\theta_{0}$ is the volumetric water content established at $x=0$ at a pressure head $h_{p} \geq 0$ and the pair $\theta_{i}<\theta_{0}, h_{i}<0$ denote the initial uniform steady state prevailing all along the porous column.

When $h_{p}=0$, the horizontal cumulative infiltration is described by the following equation

$$
i_{x}=K_{0} \int_{0}^{t} \lambda_{x=0} d t=S t^{\frac{1}{2}}
$$


where $K_{0}$ is the hydraulic conductivity when $\theta=\theta_{0}$ prevailing for all $t$ at $x=0$ and the pressure head gradient $\lambda_{x=0}$ at $x=0[5,17]$ is

$$
\lambda_{x=0}=\left(-\frac{d h}{d x}\right)_{x=0}=\frac{1}{2} t^{\frac{-1}{2}} \frac{S}{K_{0}},
$$

The imposition of the ponding head $h_{p}>0$ at $x=0$, adds the pressure head gradient and results in establishing a zone along which positive pressure heads prevail. The length of this zone is continuously increasing as the infiltration time $t$ increases. Thus, if $x_{0}$ is the value of $x$ at which the hydrostatic pressure becomes zero at time $t$, then $x_{0} \rightarrow 0$ when $t \rightarrow 0$ and $x_{0} \rightarrow \infty$ as $t \rightarrow \infty$, while the pressure head gradient $-\left(\frac{d h_{p}}{d x}\right) \equiv \lambda_{p} \rightarrow 0$ as $t \rightarrow \infty$ for all $x$ and therefore $h_{p} \rightarrow 0$ as $x_{0} \rightarrow \infty$. In this case

$$
i_{x, p}=S t^{\frac{1}{2}}+K_{0} \int_{0}^{t} \lambda_{x=0, p} d t
$$

while for all $x<x_{0}$ the hydraulic conductivity is $K_{0}$.

The pressure head gradient of the first term at the right-hand side in Equation (5) tends to zero as $t \rightarrow \infty$ and the same is true for the gradient $\lambda_{x=0, p}$. Therefore, the two terms must tend to become parallel to each other. In such a case, the integral term may be expressed in terms of $S t^{\frac{1}{2}}$ so that

$$
K_{0} \int_{0}^{t} \lambda_{x=0, p} d t=n_{x} S t^{\frac{1}{2}}
$$

where $n_{x}>0$. Thus, we may write,

$$
i_{x, p}=S t^{\frac{1}{2}}+n_{x} S t^{\frac{1}{2}}=S\left(1+n_{x}\right) t^{\frac{1}{2}}
$$

It may be mentioned that the imposition of $h_{p}$ affects the shape of the wetting front reducing it to a steeper form. From Equation (7)

$$
\frac{i_{x, p}}{t^{\frac{1}{2}}}=S\left(1+n_{x}\right)
$$

so that the value of the ratio at the left hand of Equation (8) is increasing as $n_{x}$ increases and further that this ratio is a single-valued function of the independent variable $n_{x}$.

If in conditions described by Equation (3) $x$ is replaced by $z$ then they govern, too, the vertical infiltration process. The gravitation component adds to the pressure head gradient, causes an increase of the infiltration rate and promotes the expansion of the zone with positive hydrostatic pressure. Thus, if $z_{0}$ is the depth at which the hydrostatic pressure becomes zero at a time $t$, then $z_{0} \rightarrow 0$ as $t \rightarrow 0$ and $z_{0} \rightarrow \infty$ as $t \rightarrow \infty$, and therefore

$$
\left(\frac{d z_{0}}{d t}\right)>\left(\frac{d x_{0}}{d t}\right) \text { and } z_{0}>x_{0},\left(\frac{d K_{0}}{d z}\right)>\left(\frac{d K_{0}}{d x}\right)
$$

for all finite $t$.

Poulovassilis and Argyrokastritis [15] determined that the contribution of the pressure head gradient to the vertical flow is smaller than that of the horizontal flow by a factor $a_{t}$, which is a variable depending on the infiltration time, but measurable if the soil properties $S$ and $K_{0}$ are known (Equation no. 20 from Poulovassilis and Argyrokastritis [15]). Thus, we may write,

$$
i_{z, p}=S\left(1+n_{z}\right) t^{\frac{1}{2}}-a_{t}+K_{0} t
$$

from which

$$
\frac{i_{z, p}+a_{t}-K_{0} t}{t^{\frac{1}{2}}}=S\left(1+n_{z}\right)
$$


The ratio at the left-hand side of Equation (11) is a single-valued function of the independent variable $n_{z}$.

Taking into account the analytic form of the variable $a_{t}$ (Equation no. 22 from Poulovassilis and Argyrokastritis [15])

$$
a_{t}=S t^{\frac{1}{2}}\left(1-e^{-c\left(\frac{K_{0}}{S}\right) \sqrt{t}}\right),
$$

the Equation (10) can be written as

$$
i_{z, p}=S t^{\frac{1}{2}}\left[\left(1+n_{z}\right)-\left(1-e^{-c\left(\frac{K_{0}}{S}\right) \sqrt{t}}\right)\right]+K_{0} t
$$

or

$$
i_{z, p}=S t^{\frac{1}{2}}\left(n_{z}+e^{-c\left(\frac{K_{0}}{S}\right) \sqrt{t}}\right)+K_{0} t
$$

in which $c$ is a constant fitting parameter characteristic of the porous medium.

Poulovassilis and Argyrokastritis [15] also demonstrated that the variable $a_{t}$ may be described by the following equation for small and intermediate infiltration time $t$

$$
\alpha_{t}=k t,
$$

where the slope coefficient $k$ is characteristic of the porous medium.

In that case, Equation (2) may be approximated by the Poulovassilis and Argyrokastritis (Equation no. 25 from Poulovassilis and Argyrokastritis [15]) following equation

$$
i_{z}=S t^{\frac{1}{2}}+\left(K_{0}-k\right) t
$$

\subsection{Porous Media}

Six soils ranged from sand to clay with known hydraulic properties were selected covering a wide range of soil texture. The soils studied were the Yolo light clay (YLC), a clay loam (CL), a silty loam (SiL), a sandy loam (SL), a loamy sand (LS) and a sand (S). For all soils, water retention and hydraulic conductivity curves were described by the Mualem [18]-van Genuchten [19] closed-form model. For the Yolo light clay soil, the soil parameters were obtained from Poulovassilis et al. [20] and for the other studied soils by the database included in the Hydrus-1D software package [21]. The corresponding soil

\begin{tabular}{|c|c|c|c|c|c|c|c|c|c|}
\hline \multirow[b]{2}{*}{ Soil } & \multicolumn{6}{|c|}{ Soil Parameters } & \multicolumn{3}{|c|}{ Infiltration Parameters } \\
\hline & $\begin{array}{c}\theta s \\
\left(\mathrm{~cm}^{3} \mathrm{~cm}^{-3}\right)\end{array}$ & $\begin{array}{c}\theta r \\
\left(\mathrm{~cm}^{3} \mathrm{~cm}^{-3}\right)\end{array}$ & $\begin{array}{c}\alpha \\
\left(\mathrm{cm}^{-1}\right)\end{array}$ & $\begin{array}{c}n \\
(-)\end{array}$ & $\begin{array}{c}l \\
(-)\end{array}$ & $\begin{array}{c}K s \\
\left(\mathrm{~cm} \mathrm{~h}^{-1}\right)\end{array}$ & $\begin{array}{c}S \\
\left(\mathrm{~cm} \mathrm{~h}^{-1 / 2}\right)\end{array}$ & $\begin{array}{c}c \\
(-)\end{array}$ & $\begin{array}{c}k \\
\left(\mathrm{~cm} \mathrm{~h}^{-1}\right)\end{array}$ \\
\hline YLC & 0.495 & 0.124 & 0.015 & 2.0 & 0.5 & 0.04428 & 0.7512 & 0.6468 & 0.024 \\
\hline $\mathrm{CL}$ & 0.41 & 0.095 & 0.019 & 1.31 & 0.5 & 0.26 & 0.7453 & 0.9898 & 0.1969 \\
\hline SiL & 0.450 & 0.067 & 0.02 & 1.41 & 0.5 & 0.45 & 1.2395 & 1.066 & 0.2986 \\
\hline SL & 0.41 & 0.065 & 0.075 & 1.89 & 0.5 & 4.42083 & 3.6775 & 0.73 & 1.9899 \\
\hline LS & 0.41 & 0.057 & 0.124 & 2.28 & 0.5 & 14.5917 & 6.0006 & 0.5883 & 5.9645 \\
\hline $\mathrm{S}$ & 0.43 & 0.045 & 0.145 & 2.68 & 0.5 & 29.70 & 8.9092 & 0.506 & 9.9463 \\
\hline
\end{tabular}
parameters are presented in Table 1.

Table 1. The Mualem-van Genuchten closed-form model parameters $\theta_{s}, \theta_{r}, \alpha, n$, the tortuosity factor $l$, the saturated hydraulic conductivity $K_{s}$, the sorptivity $S$ and the parameters $c$ (Equation (12)) and $k$ (Equation (15)) of the six porous media studied.

\subsection{Numerical Analysis}

Very few experimental cumulative infiltration data are available for $h_{p}>0$, which is, perhaps, due to the additional experimental difficulties for obtaining such data. For this reason, infiltration data were obtained by numerical simulation for all porous media 
studied using the Hydrus-1D software package (Department of Environmental Sciences, University of California Riverside: Riverside, CA, USA) [21].

The Hydrus-1D is one of the most common software packages that has been successfully applied in various studies worldwide for predicting soil water movement under different conditions. The HYDRUS-1D is a finite element model for simulating the one-dimensional movement of water, heat, and multiple solutes in variably saturated media. The program numerically solves the Richards equation for saturated-unsaturated water flow and Fickian-based advection-dispersion equations for both heat and solute transport [21]. The unsaturated soil hydraulic properties can be described using van Mualem-Genuchten [18,19], Brooks and Corey [22], modified van Genuchten [23], lognormal distribution model of Kosugi [24], and a dual-porosity model [25] type analytical functions. In this study, the Mualem-van Genuchten closed-form model was used.

To obtain horizontal and vertical infiltration numerical data, boundary conditions were set. Upper boundary was defined as a constant soil surface ponding depth, $\mathrm{h}_{\mathrm{p}}$, of $0,5,10,25,50,100,150$ and $200 \mathrm{~cm}$. As lower boundary of the uniform soil column, a zero-pressure head gradient was defined (free drainage). Initial pressure heads were set to $-208,-500,-300,-200,-100$ and $-100 \mathrm{~cm}$ for YLC, CL, SiL, SL, LS and S, respectively, according to soil texture.

The value of sorptivity $S$ for each porous medium was obtained using horizontal infiltration numerical data and applying the Philip's [5] equation $i_{x, n}=S t^{1 / 2}$ (Table 1).

\subsection{Tests of the Formulated Equations}

To validate the proposed Equations (7) and (14), the solutions of the $i_{x, p}$ and $i_{z, p}$ provided by these equations, respectively, were compared with numerically simulated ones, $i_{x, p, n}$ and $i_{z, p, n}$, provided by the Hydrus-1D program for horizontal and vertical infiltration, respectively.

In order to compare the proposed Equation (14) with those proposed for vertical infiltration by other researchers, the Valiantzas equation (denoted as Val) was selected and its algebraic form is given by Equation (17). It is a simple and accurate two-parameter equation, among others more sophisticated needing three or more parameters, as presented in the introduction section.

$$
i=0.5 K_{s} t+S t^{\frac{1}{2}}\left[1+\left(\frac{0.5 K_{s}}{S}\right)^{2} t\right]^{0.5},
$$

The adjustment of soil sorptivity for various soil surface ponding depths was estimated by the following Equation [11]

$$
S_{p}=\sqrt{S_{0}^{2}+2 K_{s} h_{p}\left(\theta_{s}-\theta_{i}\right)}
$$

where $S_{p}$ is the soil sorptivity for ponding depth $h_{p}, S_{0}$ for $h_{p}=0, \theta_{s}$ and $\theta_{i}$ are the water content at saturation and the initial soil water content, respectively.

\section{Results and Discussion}

In Figure 1, the horizontal cumulative infiltration curves $i_{x, p, n}$ obtained numerically for all soils examined are compared to the predicted ones $i_{x, p}$ using the Equation (7), for various $h_{p}$ values. Correspondingly, the comparison between the vertical cumulative infiltration curves $i_{z, p, n}$ obtained numerically and the predicted ones $i_{z, p}$ using the Equation (14), for various $h_{p}$ values is depicted in Figure 2. The fitting parameter $c$ in Equations (12)-(14) and the slope coefficient $k$ in Equations (15) and (16) for each soil are presented in Table 1. 

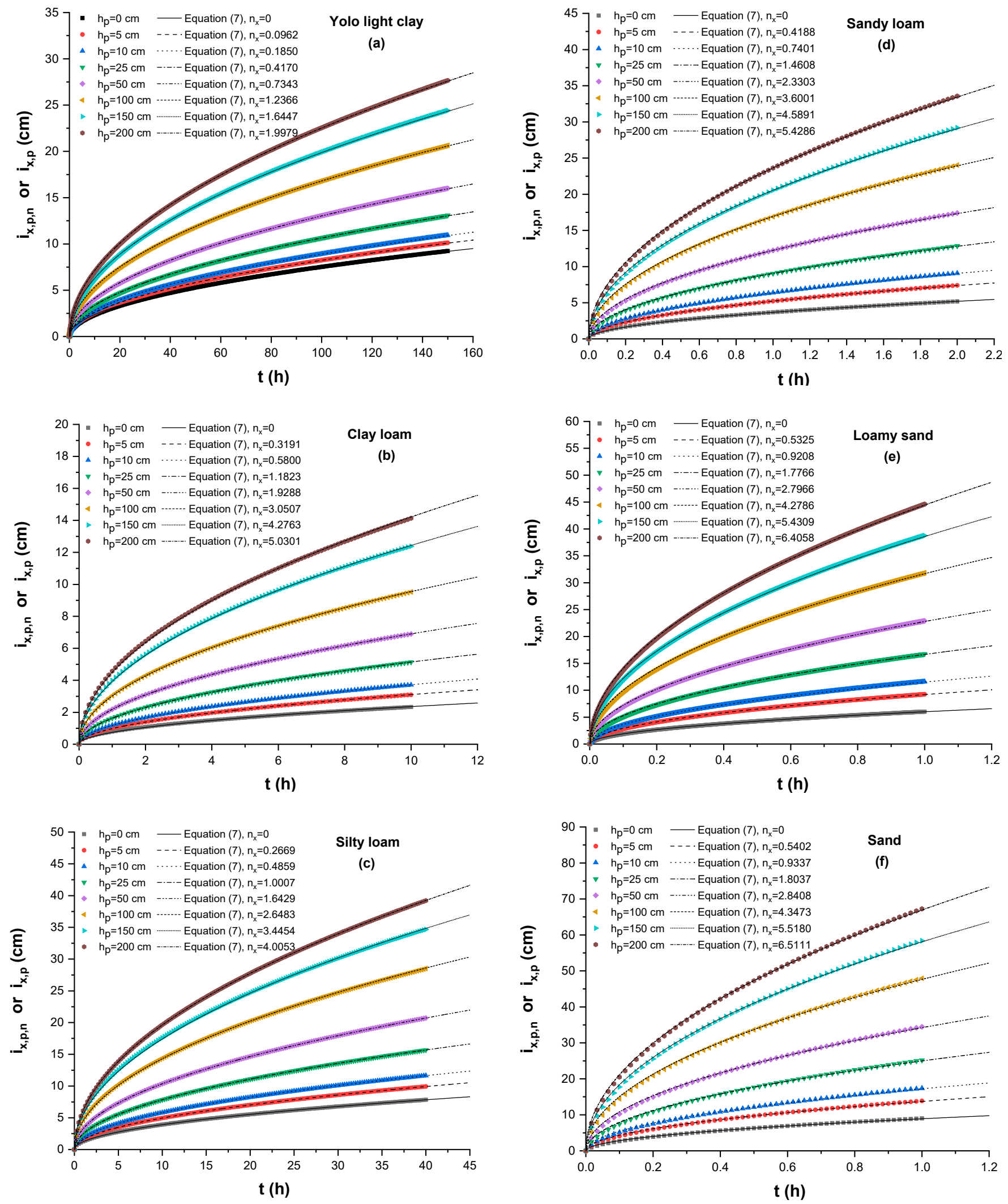

Figure 1. Comparative presentation of the horizontal cumulative infiltration numerical data $i_{x, p, n}$ and predicted ones $i_{x, p}$ using Equation (7) with time $t$ for various ponding heads $h_{p}$, for Yolo light clay (a), clay loam (b), silty loam (c), sandy loam (d), loamy sand (e) and sand (f). 

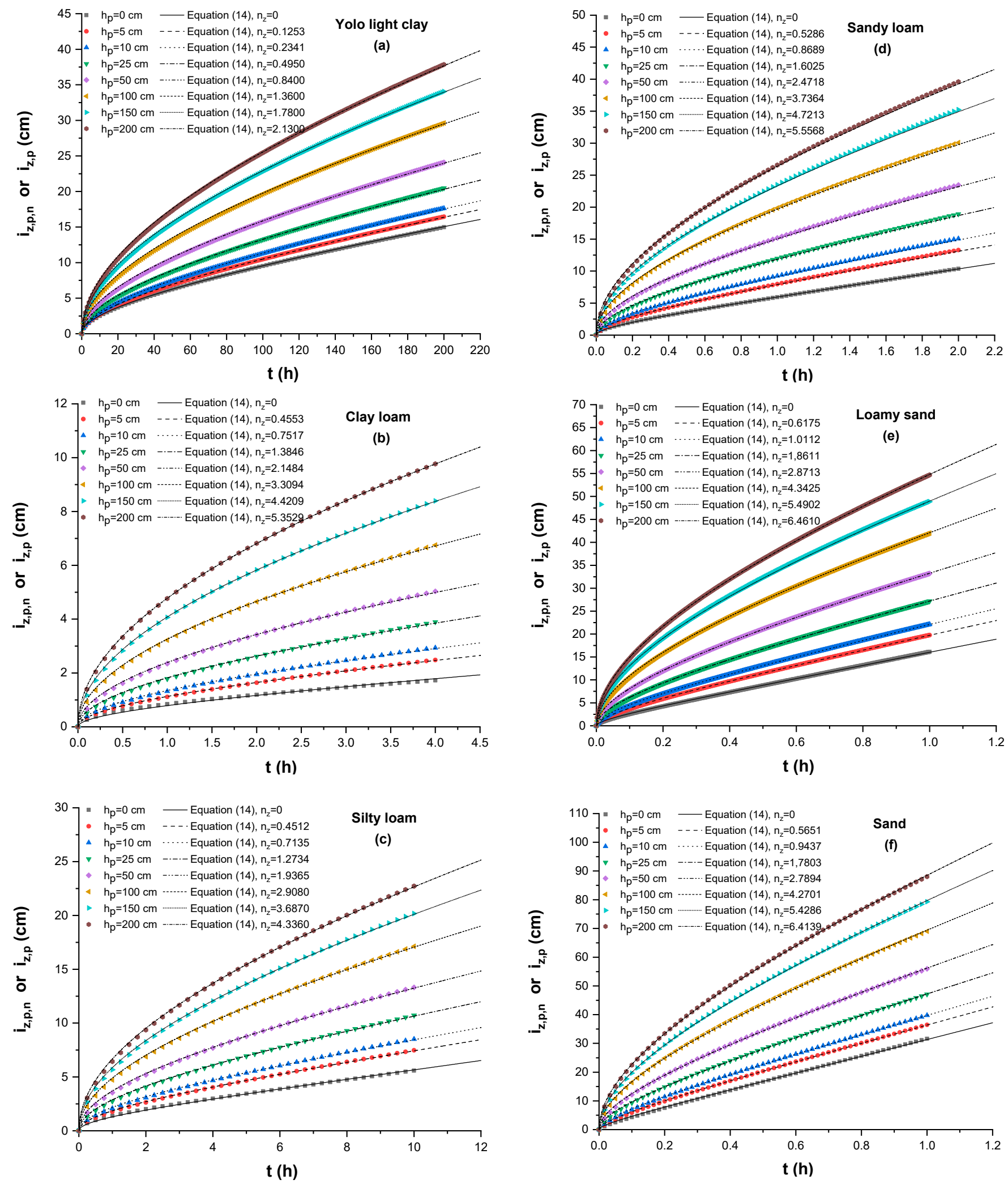

Figure 2. Comparative presentation of the vertical cumulative infiltration numerical data $i_{z, p, n}$ and predicted ones $i_{z, p}$ using Equation (14) with time $t$ for various ponding heads $h_{p}$, for Yolo light clay (a), clay loam (b), silty loam (c), sandy loam (d), loamy sand (e) and sand (f).

As shown in Figures 1 and 2, the $i_{x, p}$ and $i_{z, p}$ predicted by applying Equations (7) and (14), for the horizontal and vertical infiltration, respectively, are in close agreement 
with those produced numerically by Hydrus-1D. Furthermore, the proposed equations (Equations (7) and (14)) were tested for their accuracy with the numerical data using the indices of Root Mean Square Error (RMSE) and Index of Agreement (d) [26]:

$$
\begin{gathered}
d=1-\frac{\sum_{j=1}^{N}\left(i_{n, j}-i_{\text {pred }, j}\right)^{2}}{\sum_{j=1}^{N}\left(\left|i_{\text {pred }, j}-\overline{i_{n}}\right|+\left|i_{n, j}-\overline{i_{n}}\right|\right)^{2}}, 0 \leq d \leq 1, \\
R M S E=\sqrt{\frac{\sum_{j=1}^{N}\left(i_{n, j}-i_{\text {pred }, j}\right)^{2}}{N}},
\end{gathered}
$$

where $i_{n, j}$ and $i_{\text {pred,j }}$ are the numerical cumulative infiltration values and the predicted ones by the proposed Equation (7) or (14), respectively, $\overline{i_{n}}$ is the mean of numerical values and $N$ is the number of values.

As shown in Table 2, both the small values of RMSE and the values of $d$ approaching 1 indicate the accurate match of the proposed equations (Equations (7) and (14)) to the numerical data for all porous media studied.

Table 2. Root Mean Square Error (RMSE) and Index of Agreement ( $d$ ) for testing the accuracy of the proposed Equations (7) and (14) with the numerical data for various ponding heads $h_{p}$ for the six

\begin{tabular}{|c|c|c|c|c|c|c|c|c|c|c|c|c|}
\hline \multirow{2}{*}{$\begin{array}{c}h_{p} \\
(\mathrm{~cm})\end{array}$} & \multicolumn{2}{|c|}{ YLC } & \multicolumn{2}{|c|}{ CL } & \multicolumn{2}{|c|}{ SiL } & \multicolumn{2}{|c|}{ SL } & \multicolumn{2}{|c|}{ LS } & \multicolumn{2}{|l|}{ S } \\
\hline & RMSE & $d$ & RMSE & $d$ & RMSE & $d$ & RMSE & $d$ & RMSE & $d$ & RMSE & $d$ \\
\hline \multicolumn{13}{|c|}{ Horizontal infiltration using Equation (7) } \\
\hline 0 & 0.036 & 0.999 & 0.025 & 0.999 & 0.011 & 0.999 & 0.015 & 0.999 & 0.025 & 0.999 & 0.083 & 0.999 \\
\hline 5 & 0.046 & 0.999 & 0.169 & 0.988 & 0.003 & 1.000 & 0.030 & 0.999 & 0.069 & 0.999 & 0.151 & 0.999 \\
\hline 10 & 0.052 & 0.999 & 0.267 & 0.980 & 0.002 & 1.000 & 0.047 & 0.999 & 0.092 & 0.999 & 0.225 & 0.999 \\
\hline 25 & 0.064 & 0.999 & 0.464 & 0.970 & 0.001 & 1.000 & 0.075 & 0.999 & 0.127 & 0.999 & 0.242 & 0.999 \\
\hline 50 & 0.079 & 0.999 & 0.669 & 0.966 & 0.012 & 0.999 & 0.103 & 0.999 & 0.157 & 0.999 & 0.290 & 0.999 \\
\hline 100 & 0.101 & 0.999 & 0.916 & 0.966 & 0.072 & 0.999 & 0.132 & 0.999 & 0.181 & 0.999 & 0.332 & 0.999 \\
\hline 150 & 0.117 & 0.999 & 0.523 & 0.993 & 0.137 & 0.999 & 0.149 & 0.999 & 0.185 & 0.999 & 0.353 & 0.999 \\
\hline 200 & 0.129 & 0.999 & 0.667 & 0.991 & 0.026 & 0.999 & 0.159 & 0.999 & 0.197 & 0.999 & 0.362 & 0.999 \\
\hline \multicolumn{13}{|c|}{ Vertical infiltration using Equation (14) } \\
\hline 0 & 0.045 & 0.999 & 0.042 & 0.998 & 0.059 & 0.999 & 0.017 & 0.999 & 0.072 & 0.999 & 0.197 & 0.999 \\
\hline 5 & 0.064 & 0.999 & 0.078 & 0.996 & 0.045 & 1.000 & 0.117 & 0.999 & 0.104 & 0.999 & 0.176 & 0.999 \\
\hline 10 & 0.091 & 0.999 & 0.126 & 0.993 & 0.058 & 0.999 & 0.140 & 0.999 & 0.112 & 0.999 & 0.215 & 0.999 \\
\hline 25 & 0.127 & 0.999 & 0.233 & 0.987 & 0.072 & 0.999 & 0.171 & 0.999 & 0.131 & 0.999 & 0.192 & 0.999 \\
\hline 50 & 0.161 & 0.999 & 0.343 & 0.984 & 0.079 & 0.999 & 0.199 & 0.999 & 0.148 & 0.999 & 0.212 & 0.999 \\
\hline 100 & 0.185 & 0.999 & 0.452 & 0.984 & 0.089 & 0.999 & 0.229 & 0.999 & 0.155 & 0.999 & 0.238 & 0.999 \\
\hline 150 & 0.211 & 0.999 & 0.318 & 0.995 & 0.099 & 0.999 & 0.246 & 0.999 & 0.148 & 0.999 & 0.252 & 0.999 \\
\hline 200 & 0.198 & 0.999 & 0.217 & 0.998 & 0.114 & 0.999 & 0.259 & 0.999 & 0.149 & 0.999 & 0.262 & 0.999 \\
\hline
\end{tabular}
porous media studied.

It may be noted that the hydraulic properties $S$ and $K_{0}$ present in Equations (7) and (14) can be determined from an available cumulative infiltration curve for vertical infiltration under zero ponding head [15]. Thus, Equation (7) contains one unknown, $n_{x}$, which depends on the value of ponding head $h_{p}$ (Figure 1a-f) and Equation (14) contains the unknown variable $n_{z}$ which also depends on the value of ponding head $h_{p}$ as shown in Figure 2a-f. It is seen from these figures that $n_{z}>n_{x}$, and the rather small difference between them may be explained on the basis of the relationships (7) and (10). We have not reached an analytical expression relating $h_{p}$ and $n$ for both cases of infiltration (horizontal and vertical). However, it is found that the plotting of $\log h_{p}$ versus $\log n$ produces, approximately, a straight line (Figure 3). Thus, if two pairs $\left(h_{p}-n\right)_{1}$ and $\left(h_{p}-n\right)_{2}$ are determined, then the relationship $\left(h_{p}, n\right)$ may be approached for all such pairs. 

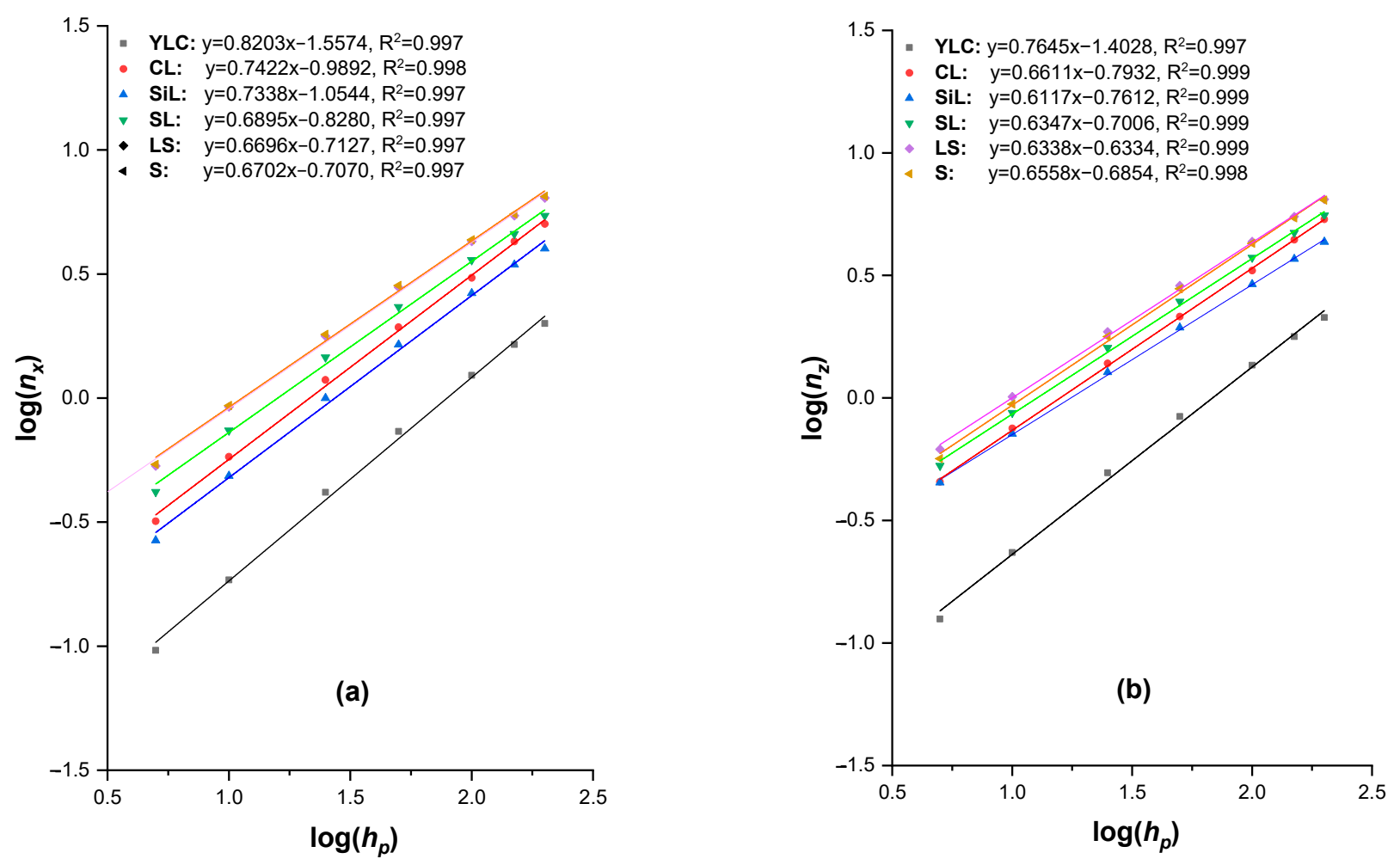

Figure 3. Relationships between (a) the parameter $n_{x}$ of the Equation (7) and ponding head $h_{p}$ for horizontal infiltration and (b) the parameter $n_{z}$ of the Equation (14) and ponding head $h_{p}$ for vertical infiltration (b), for all porous media studied.

The vertical cumulative infiltration data $i_{z, p}$ with time $t$ obtained by the proposed Equation (14) and the Valiantzas equation (Equation (17)) for $h_{p}=0$ and various soil ponding heads $h_{p}$, are presented in Figure 4 and the index of RMSE values between the two equations are presented in Table 3.

From Figure 4 and the RMSE values, it is obvious that there are differences in the estimation of vertical cumulative data $i_{z, p}$ between the two procedures. This difference is not systematical, since for $h_{p}=0$ the Val (Equation (17)) compared to Equation (14) overestimated the vertical cumulative infiltration data $i_{z, p}$ while for $h_{p}>0$ the Val generally underestimated the $i_{z, p}$ values.

Specifically, the Val systematically overestimated the $i_{z, p}$ data for $h_{p}=0$ for all the tested porous media. There is a higher difference between the two equations for the fine-textured soils (YCL, SiL) compared to the coarse-textured ones (LS, S). The overestimation of the $i_{z, p}$ data for $h_{p}=0$, as has been shown by Poulovassilis and Argyrokastritis [15], is attributed to the non-incorporation of the actual contribution of the pressure head gradient term to this model.

For all the other ponding heads $h_{p}>0$, the Val generally underestimated the $i_{z, p}$ data for all the tested porous media. The underestimation of Val compared to Equation (14) presents higher differences for the coarse-textured soils (S, LS), for which there is also a gradual increase of this difference as the $h_{p}$ values increase in the same porous media. For the finer porous media, the Val generally underestimated the $i_{z, p}$ but for an intermediate value of $h_{p}$, different for each porous medium, the Val gives similar results to Equation [14]. The higher differences between the two equations (Equation (14) and Val) for the ponding depths $h_{p}>0$ are observed for coarser materials compared to the finer ones. Specifically, the underestimation of Val compared to Equation (14) for $h_{p}>0$ may be attributed to the estimation of $S_{p}$ for the different $h_{p}$ and also in the way that the needed parameter of $\theta_{i}$ is estimated. 

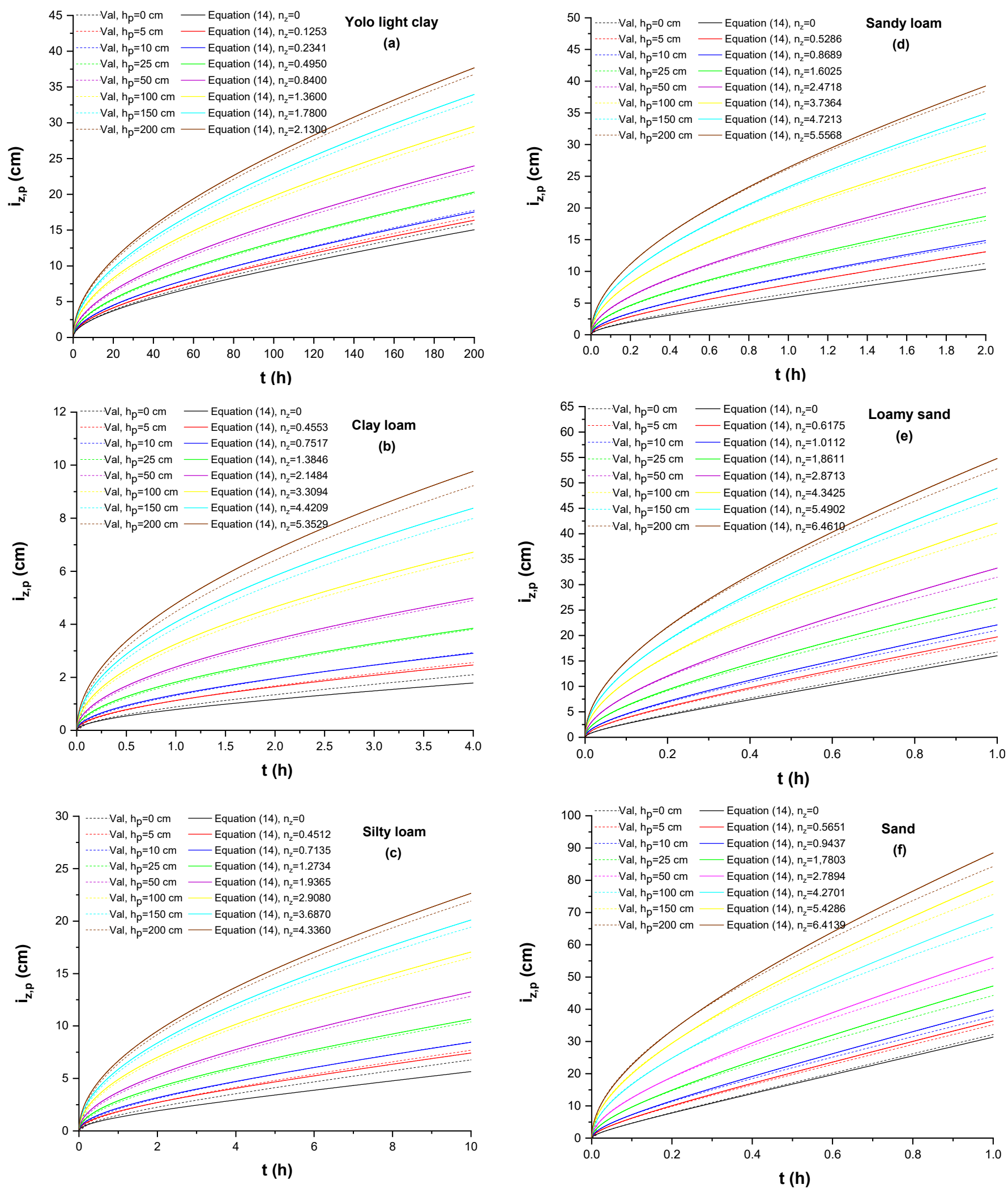

Figure 4. Comparative presentation of the vertical cumulative infiltration data $i_{z, p}$ predicted by the proposed Equation (14) and the Valiantzas equation [11] with time $t$ for various ponding heads $h_{p}$, for Yolo light clay (a), clay loam (b), silty loam (c), sandy loam (d), loamy sand (e) and sand (f). 
Table 3. Root Mean Square Error (RMSE) values from comparing the vertical cumulative infiltration data $i_{z, p}$ predicted by the proposed Equation (14) and the Valiantzas Equation [11] for various ponding heads $h_{p}$ for the six porous media studied.

\begin{tabular}{ccccccc}
\hline $\boldsymbol{h}_{\boldsymbol{p}} \mathbf{( \mathbf { c m } )}$ & $\mathbf{Y L C}$ & $\mathbf{C L}$ & $\mathbf{S i L}$ & $\mathbf{S L}$ & $\mathbf{L S}$ & $\mathbf{S}$ \\
\hline 0 & 0.757 & 0.194 & 0.728 & 0.579 & 0.441 & 0.472 \\
5 & 0.288 & 0.043 & 0.159 & 0.025 & 0.379 & 0.696 \\
10 & 0.119 & 0.129 & 0.051 & 0.182 & 0.601 & 1.319 \\
25 & 0.173 & 0.278 & 0.191 & 0.341 & 0.825 & 1.536 \\
50 & 0.407 & 0.423 & 0.282 & 0.398 & 0.926 & 1.783 \\
100 & 0.555 & 0.617 & 0.356 & 0.407 & 0.978 & 1.935 \\
150 & 0.641 & 0.603 & 0.449 & 0.396 & 0.998 & 1.992 \\
200 & 0.611 & 0.606 & 0.487 & 0.379 & 0.994 & 2.021 \\
\hline
\end{tabular}

\section{Conclusions}

The study of infiltration under ponded conditions is of great interest in agricultural lands. However, there are no studies that have considered the actual contribution of the pressure head gradient to the flow in their analyses.

To fill that scientific gap, two simple equations are proposed, to describe the horizontal and vertical infiltration under various ponding heads, incorporating the actual contribution of the pressure head gradient to the flow.

The accuracy of the proposed equations was validated using horizontal and vertical numerical infiltration data for six soils, covering a wide range of soil textures.

The soil sorptivity and saturated hydraulic conductivity, which are included in the proposed equations, can be determined from an available vertical cumulative infiltration under zero ponding head. Thus, both the horizontal and vertical proposed equations contain one unknown parameter each, $n_{x}$ and $\mathrm{n}_{\mathrm{z}}$ respectively, which depend on the value of ponding head $h_{p}$. The plotting of $\log h_{\mathrm{p}}$ versus $\log n$ produces, approximately, a straight line.

Finally, the proposed vertical infiltration equation was compared to that of Valiantzas which does not incorporate the actual contribution of the pressure head gradient to the flow and differences were observed in all porous media studied. The vertical cumulative infiltration data obtained by Valiantzas equation are overestimated for $h_{p}=0$ and are underestimated for $h_{p}>0$.

Author Contributions: Conceptualization, I.A.; methodology, I.A.; software, I.A., M.P. and P.A.L.; validation, I.A., M.P. and P.A.L.; formal analysis, I.A., M.P. and P.A.L.; investigation, I.A., M.P. and P.A.L.; data curation, I.A., M.P. and P.A.L.; writing-review and editing, I.A., M.P. and P.A.L. All authors have read and agreed to the published version of the manuscript.

Funding: This research received no external funding.

Institutional Review Board Statement: Not applicable.

Informed Consent Statement: Not applicable.

Data Availability Statement: No new data were created or analyzed in this study. Data sharing is not applicable to this article.

Conflicts of Interest: The authors declare no conflict of interest.

\section{References}

1. Philip, J.R. The theory of infiltration: 6 Effect of water depth over soil. Soil Sci. 1958, 85, 278-286. [CrossRef]

2. Philip, J.R. The theory of infiltration: 7. The infiltration equation and its solution. Soil Sci. 1958, 85, 333-337. [CrossRef]

3. Green, W.A.; Ampt, G.A. Studies on soils physics: 1. The flow of air and water through soils. J. Agric. Sci. 1911, 4, 1-24.

4. Brutsaert, W. Vertical infiltration in dry soil. Water Resour. Res. 1977, 13, 363-368. [CrossRef]

5. Philip, J.R. The theory of infiltration: 1. The infiltration equation and its solution. Soil Sci. 1957, 83, 345-357. [CrossRef]

6. Parlange, J.-Y.; Lisle, I.; Braddock, R.D.; Smith, R.E. The three-parameter infiltration equation. Soil Sci. 1982, 133, 337-341. [CrossRef] 
7. Parlange, J.-Y.; Haverkamp, R.; Touma, J. Infiltration under ponded conditions: 1. Optimal analytical solution and comparison with experimental observations. Soil Sci. 1985, 139, 305-311. [CrossRef]

8. Haverkamp, R.; Parlange, J.-Y.; Starr, J.L.; Schmitz, G.; Fuentes, C. Infiltration under ponded conditions: 3. A predictive equation based on physical parameters. Soil Sci. 1990, 149, 292-300. [CrossRef]

9. Swartzendruber, D. A quasi-solution of Richards' equation for the downward infiltration of water into soil. Water Resour. Res. 1987, 23, 809-817. [CrossRef]

10. Stroosnijder, L. Infiltratie en Herverdeling van Water in Gronde (Infiltration and Redistribution of Water in Soils). Versl. Landbouwkd. Onderz. 847. 1976. Available online: https:// core.ac.uk/download/pdf/29386787.pdf (accessed on 6 September 2021).

11. Valiantzas, J.D. New linearized two-parameter infiltration equation for direct determination of conductivity and sorptivity. J. Hydrol. 2010, 384, 1-13. [CrossRef]

12. Talsma, T.; Parlange, J.-Y. One-dimensional vertical infiltration. Aust. J. Soil Res. 1972, 10, 143-150. [CrossRef]

13. Haverkamp, R.; Kutilek, M.; Parlange, J.-Y.; Rendon, L.; Krejca, M. Infiltration under ponded conditions: 2. Infiltration equations tested for parameter time-dependence and predictive use. Soil Sci. 1988, 145, 317-329. [CrossRef]

14. Barry, D.A.; Parlange, J.-Y.; Haverkamp, R.; Ross, J.P. Infiltration under ponded conditions: 4 . An explicit predictive infiltration formula. Soil Sci. 1995, 160, 8-17. [CrossRef]

15. Poulovassilis, A.; Argyrokastritis, I. A new approach for studying vertical infiltration. Soil Res. 2020, 58, 509-518. [CrossRef]

16. Philip, J.R. The theory of infiltration: 4. Sorptivity and algebraic infiltration equations. Soil Sci. 1957, 84, 257-264. [CrossRef]

17. Philip, J.R. Numerical solution of equations of the diffusion type with diffusivity concentration dependent. Trans. Faraday Soc. 1955, 51, 885-892. [CrossRef]

18. Mualem, Y. A new model for predicting the hydraulic conductivity of unsaturated porous media. Water Resour. Res. 1976, 12, 513-522. [CrossRef]

19. Van Genuchten, M.T. A closed-form equation for predicting the hydraulic conductivity of unsaturated soils. Soil Sci. Soc. Am. J. 1980, 44, 892-898. [CrossRef]

20. Poulovassilis, A.; Elmaloglou, S.; Kerkides, P.; Argyrokastritis, I. A variable sorptivity infiltration equation. Water Resour. Manag. 1989, 3, 287-298. [CrossRef]

21. Šimůnek, J.; Šejna, M.; Saito, H.; Sakai, M.; van Genuchten, M.T. The HYDRUS-1D Software Package for Simulating the OneDimensional Movement of Water, Heat, and Multiple Solutes in Variably-Saturated Media, Version 4.0, Hydrus Series 3; Department of Environmental Sciences, University of California Riverside: Riverside, CA, USA, 2008.

22. Brooks, R.H.; Corey, A.T. Hydraulic Properties of Porous Media; Hydrology Paper No. 3; Colorado State University: Fort Collins, CO, USA, 1964.

23. Vogel, T.; Císlerová, M. On the reliability of unsaturated hydraulic conductivity calculated from the moisture retention curve. Transp. Porous Media 1988, 3, 1-15. [CrossRef]

24. Kosugi, K. Lognormal distribution model for unsaturated soil hydraulic properties. Water Resour. Res. 1996, 32, $2697-2703$. [CrossRef]

25. Durner, W. Hydraulic conductivity estimation for soils with heterogeneous pore structure. Water Resour. Res. 1994, 32, 211-223. [CrossRef]

26. Willmott, C.J. Some comments on the evaluation of model performance. Bull. Am. Meteorol. Soc. 1982, 62, 1309-1313. [CrossRef] 